\title{
Review
}

\section{Liquid Biopsy-Analysis of Circulating Tumor DNA (ctDNA) in Bladder Cancer}

\author{
Tilman Todenhöfer ${ }^{\mathrm{a}, 1}$, Werner J. Struss ${ }^{\mathrm{b}, 1}$, Roland Seiler ${ }^{\mathrm{c}}$, Alexander William Wyatt ${ }^{\mathrm{b}}$ \\ and Peter C. Black ${ }^{\mathrm{b}, *}$ \\ ${ }^{a}$ Department of Urology, University Hospital, Tübingen, Germany \\ ${ }^{\mathrm{b}}$ Vancouver Prostate Centre, University of British Columbia, Vancouver, BC, Canada \\ ${ }^{\mathrm{c}}$ Inselspital Bern, Bern, Switzerland
}

\begin{abstract}
Recent advances in DNA profiling techniques have enabled sensitive detection of tumor-associated genomic aberrations in peripheral blood. This type of minimally-invasive molecular interrogation has the potential to guide subsequent treatment selection. The potential utility of ctDNA in bladder cancer (BC) is bolstered by the high somatic mutation rate, meaning that very small numbers of genes or target regions can be informative. First reports indicate that analysis of ctDNA may represent a sensitive method for disease surveillance in patients with different stages of BC. Moreover, recent evidence suggests that ctDNA analysis reveals previously unknown genomic alterations in metastatic patients. Since some of these gene alterations represent therapeutic targets, ctDNA analysis provides an attractive tool to guide individualized therapy in $\mathrm{BC}$.
\end{abstract}

Keywords: Biomarker, blood, ctDNA, cfDNA, next generation sequencing, PCR

\section{INTRODUCTION}

The analysis of tumor-associated genomic alterations in circulating tumor DNA (ctDNA) is rapidly developing as a platform for biomarker discovery in patients with advanced malignancies $[1,2]$. Initial studies of ctDNA in the 1970s described an association between ctDNA burden and tumor aggressiveness [3], but progress was hampered by technological constraints. However, advances in digital droplet polymerase chain reaction (PCR) and highly sensitive next-generation sequencing (NGS) now allow capture and analysis of ctDNA even when highly diluted by non-malignant

\footnotetext{
${ }^{1}$ Contributed equally.

${ }^{*}$ Correspondence to: Peter C. Black, The Vancouver Prostate Centre, 2660 Oak Street, Vancouver, BC, V6H 3Z6, Canada. Tel.: +1 604875 4818; Fax: +1 604875 5654; E-mail: pblack@mail. ubc.ca.
}

cell-free DNA (cfDNA) [4, 5]. Recent studies of several solid cancers suggest that somatic alterations detected in ctDNA are reflective of those present in matched tumor tissue: proposing ctDNAbased profiling as a practical method to assess the tumor genome independently of direct tissue analysis $[4,6]$. This holds particular promise in patients with relapsed or metastatic disease who rarely undergo biopsy of recurrent or metastatic lesions.

Emerging data suggests that ctDNA analysis will augment the management of patients with bladder cancer (BC) [7-10]. Our review summarizes recent progress and preliminary data supporting clinical utility of ctDNA in BC. In particular, we highlight the remarkable potential for ctDNA to aid disease surveillance across different stages of $\mathrm{BC}$ and the power of ctDNA to provide insights into the metastatic $\mathrm{BC}$ genome in real-time. 


\section{METHODS}

We reviewed current literature nonsystematically using the National Library of Medicine database (http://www.pubmed.gov). A Medline search was performed using the following terms: urothelial carcinoma, bladder cancer, liquid biopsy, cell free DNA, circulating tumor DNA, cfDNA, ctDNA. Articles were considered between 2010 and 2017. References were also secondarily extracted from identified articles. In addition, recent studies presented at the Annual Meeting of the American Society for Clinical Oncology (ASCO) were included.

\section{DETECTION OF CTDNA: METHODOLOGIC CONSIDERATIONS}

Fragments of cell-free DNA (cfDNA) are shed into the circulation by both tumor cells and nonmalignant cells, especially hematopoietic cells [11]. The enduring challenge for accurate profiling of the tumor-derived proportion of cfDNA, is that the relative quantity of ctDNA varies significantly by disease state and between patients. Unlike a direct tissue biopsy where a pathologist can estimate tumor cellularity prior to genomic profiling, the ctDNA fraction of any given plasma cfDNA sample is much less predictable. Clues can be drawn from a patient's overall disease burden since ctDNA fractions correlate with clinical metrics of tumor volume such as serum alkaline phosphatase or lactate dehydrogenase [12]. In metastatic patients where the ctDNA fraction can be above $50 \%$ of all cfDNA, the total extracted DNA yield from plasma can also inform on ctDNA fraction [10]. However, in patients with low disease volume or those with minimal residual disease after therapy, ctDNA may be extremely rare or not be present at all in a small plasma sample. It is important to note that the lower bound for detecting ctDNA is governed by the total amount of cfDNA obtained. In our recent study, the average cfDNA yield in patients with localized muscle-invasive bladder cancer (MIBC) not receiving therapy was less than $10 \mathrm{ng}$ per $\mathrm{mL}$ of plasma (representing approximately 1500 diploid genomes) [10]. This means that, even with the latest technologies, for ctDNA to be realistically detected in 1-2 $\mathrm{mL}$ of plasma, it must be present at fractions above 1/1500.

In most studies to date, alterations in ctDNA have been detected using either polymerase chain reaction (PCR)-based methods or targeted next-generation sequencing approaches (NGS; Table 1). The selection of the most appropriate method for cfDNA analysis must consider cost, number of genomic alterations and tumor burden. It is not possible to maintain costeffectiveness while simultaneously informing upon both very low ctDNA fractions and a broad panel of genomic regions. Therefore, approaches are typically tailored for the disease state (and ctDNA fraction) in question. Assays specifically capturing known mutations permit the detection of mutant alleles in patients with ctDNA fractions of 0.01 to $1 \%$ [8, 13]. Of course, this must be enabled by either patient-specific a priori knowledge (e.g. from archival tissue profiling) or plausible presence of recurrent single nucleotide mutations (e.g. PIK3CA p.E545K). Droplet digital PCR (ddPCR) or bead-based PCR has been used well to this end, but is challenging to multiplex beyond a handful of mutations [7-9]. Similarly, ultradeep NGS incorporating unique molecular identifiers (UMIs), also known as barcodes, can reveal very 'diluted' mutations across entire genes, but, due to the high sequencing depth required, costs escalate quickly if scaled beyond a few genes [14]. Importantly however, because of the very high mutation rate in MIBC, both methodologies are suitable and even a very small targeted panel could be effective. For example, over $90 \%$ of MIBC patients have at least one mutation in the hotspot regions of PIK3CA, the promoter region of TERT, or the TP53 gene, so a panel covering just those regions can still expect to be informative in most MIBC patients [10, 15, 16].

Broader next-generation sequencing panels allow more exploratory analyses of the genomic landscape, including genes disrupted by copy number changes and rearrangements (such as FGFR3 fusions) [10]. At present this approach is likely only relevant for patients with high ctDNA fractions, such as those with progressing metastatic disease. Indeed, we have shown that whole exome sequencing yields robust results in a significant minority of metastatic BC patients. Unfortunately, with current technology the detection of single gene copy number changes is much more challenging at ctDNA fractions less than 20-30\%, due to multiplicative noise [6, 17]. Although shifts in the allelic frequency of germline SNPs can help identify single copy gains or losses at slightly lower ctDNA fractions, we can draw lessons from fetal cfDNA screens of maternal plasma where chromosomal aneuploidies are only confidently 'called' at fetal cfDNA fractions above $10 \%$.

Ultimately the technical challenges of cfDNA analysis must be weighed against those faced by direct 
Table 1

Overview of techniques used for analysis of cell free DNA (cfDNA)

\begin{tabular}{|c|c|c|c|c|c|}
\hline Technique & Overview & $\begin{array}{l}\text { Minimum } \% \text { of } \\
\text { ctDNA required (of } \\
\text { total cfDNA) }\end{array}$ & Advantages & Disadvantages & Ref. \\
\hline Digital droplet PCR & $\begin{array}{l}\text { Detection of } \\
\text { previously known } \\
\text { or frequent } \\
\text { mutations/CNVs } \\
\text { (e.g. androgen } \\
\text { receptor in prostate } \\
\text { cancer) }\end{array}$ & $\begin{array}{l}\sim 0.01 \text { (mutations) } \\
\sim 10 \% \text { (copy number } \\
\quad \text { alterations*) }\end{array}$ & $\begin{array}{l}\text { High sensitivity, no } \\
\text { NGS platform } \\
\text { required }\end{array}$ & $\begin{array}{l}\text { Limited number of } \\
\text { targets assessable in } \\
\text { parallel }\end{array}$ & {$[8,9,48]$} \\
\hline $\begin{array}{l}\text { Ultra-deep } \\
\text { sequenc-ing with } \\
\text { UMIs }\end{array}$ & $\begin{array}{l}\text { Detection of unknown } \\
\text { mutations in } 1-10 \\
\text { genes or regions }\end{array}$ & $\sim 0.01$ (mutations) & $\begin{array}{l}\text { High sensitivity, can } \\
\text { inform on multiple } \\
\text { genes }\end{array}$ & $\begin{array}{l}\text { Either limited to } \\
\sim 1-10 \text { genes with } \\
\text { coverage of only } \\
\text { few kbps or high } \\
\text { costs in case of } \\
\text { higher coverage } \\
\text { (Mbps) }\end{array}$ & {$[14,27,49]$} \\
\hline $\begin{array}{l}\text { Standard targeted } \\
\text { NGS (without } \\
\text { UMIs) }\end{array}$ & $\begin{array}{c}\text { Detection of unknown } \\
\text { mutations/CNVs in } \\
\text { a preselected panel } \\
\text { of genes or regions }\end{array}$ & $\begin{array}{l}2 \text { (i.e. mutation } \\
\text { detection at } 1 \% \\
\text { VAF); } 10-20 \% \text { for } \\
\text { CNV detection } \\
\text { (varies by nature } \\
\text { and extent of } \\
\text { alteration) }\end{array}$ & $\begin{array}{l}\text { Broad target regions } \\
\text { assessable, low } \\
\text { input required }\end{array}$ & $\begin{array}{l}\text { No detection of low } \\
\text { abundance } \\
\text { mutations }\end{array}$ & {$[10,43,47]$} \\
\hline Standard WES/WGS & $\begin{array}{l}\text { Detection of unknown } \\
\text { mutations/CNVs }\end{array}$ & 20 & $\begin{array}{l}\text { Assessment of entire } \\
\text { exome/genome }\end{array}$ & $\begin{array}{l}\text { High ctDNA fraction } \\
\text { required }\end{array}$ & {$[10]$} \\
\hline
\end{tabular}

CNV: copy number variation; NGS: next generation sequecing; PCR: polymerase chain reaction; SNP: single nucleotide polymorphism; WES: whole exome sequencing; WGS: whole genome sequencing; VAF = variant allele frequency; UMI = unique molecular identifiers (barcodes); *not yet demonstrated in bladder cancer but shown in other malignancies.

tissue biopsy, which also suffers from variable failure rates, issues of tumor cellularity, and complications derived from formalin-fixation. Blood samples are much more practical to obtain than tissue samples, and blood-based assays are therefore more easily scalable to large patient cohorts. Furthermore, in the event of a negative result (e.g. no ctDNA detected), repeat sampling is clinically feasible.

\section{USING CTDNA FOR BLADDER CANCER SURVEILLANCE}

The first reports exploring ctDNA in BC employed ddPCR for highly sensitive detection of distinct $\mathrm{BC}$-associated mutations in plasma, specifically for monitoring patients for relapse in the aftermath of local disease intervention [8,9]. BirkenkampDemtröder et al. demonstrated that low ctDNA fractions in non-muscle-invasive BC (NMIBC) are no barrier to ctDNA detection and clinical utility [8]. In their 2016 report, the authors initially employed WES to identify somatic mutations in primary tumor tissue resected from each patient tumor. Up to six patient-specific mutations from each tumor specimen were then incorporated into a series of ddPCR assays capable of detecting one mutated gene allele from 6000 background copies of the wildtype gene $(<0.02 \%)$. With this level of sensitivity the authors were able to detect ctDNA early in the disease course in 9 of 12 patients, including patients with Ta disease. Applying these personalized ddPCR assays longitudinally, at multiple time points in the course of each patient's disease, demonstrated ctDNA was detectable prior to clinical demonstration of progression in 4 of 6 patients who ultimately showed clinical progression (it should be noted that all 12 patients with NMIBC in this study developed disease recurrence, and the other 6 progressed to muscle invasive or metastatic disease). Remarkably, in one patient ctDNA was detected 1 year before clinical progression, and assay-specific genome equivalents increased fivefold over this time period. Indeed, average ctDNA burdens were higher in patients who progressed than those who simply recurred. Furthermore, the authors also found high levels of tumor DNA in the urine of all patients with progressive disease, even in the absence of detectable plasma ctDNA. The study strongly supports the use of plasma and urine ctDNA to monitor for BC disease recurrence and progression, and is consistent with recent 
data from breast cancer, where digital PCR assays for ctDNA detection can predict relapse after local therapy [4].

Designing personalized ddPCR assays is extremely labour- and cost-intensive (WES of tissue) and requires patient tissue. Given the high mutation rate of some genes in $\mathrm{BC}$, a clear alternative for detecting low ctDNA fractions (and therefore, residual disease) is to develop ddPCR assays targeting a handful of specific genomic alterations with known recurrence. For example, PI3KCA, TERT, FGFR3, RAS family members, and TP53 all contain specific base pairs that are recurrently mutated in BC, known as mutation 'hotspots'. Accordingly, the same Danish group as above applied a non-personalized ddPCR approach in two retrospective patient cohorts. One cohort included 363 patients with NMIBC, and the other included 403 patients undergoing radical cystectomy for predominantly (90\%) MIBC. In this study, Christensen et al. selected two of the most commonly mutated genes in $\mathrm{BC}-F G F R 3$ and $P I K 3 C A$ - and developed ddPCR assays for the sensitive detection of their hotspot mutations [18, 19]. However, these two genes alone are not sufficient to represent all patients with $\mathrm{BC}$, and therefore only $36 \%$ of NMIBC and $11 \%$ of cystectomy patients in this study actually harbored one or both mutations in their archival tumor tissue. Since only 2 of 7 patients in the NMIBC cohort had detectable ctDNA at the time of disease progression, the analysis was not expanded to include all NMIBC patients. In the cystectomy cohort, ctDNA levels were associated with recurrence-free and overall survival. The BC recurred in $8 / 9$ patients with detectable ctDNA but only $6 / 18$ with no detectable ctDNA. The reduced detection rate (particularly for NMIBC), likely reflects the more constrained ddPCR approach, and would likely be improved with the addition of further hotspot mutations in other recurrently mutated BC genes.

The most recent study from the Aarhus group focused on ctDNA to monitor treatment response and disease relapse in patients with MIBC. Predesigned ddPCR assays were used to screen for hotspot mutations in PIK3CA and FGFR3 in tissue samples collected prospectively from 60 patients, of whom 19 were found to have mutations. In addition, the authors performed WES in tumor tissue from 24 of the same patients to develop personalized ddPCR assays. Combined pre-designed and personalized ddPCR assays were used to monitor 26 patients undergoing neoadjuvant chemotherapy followed by radical cystectomy $(n=24)$ or systemic chemotherapy for metastatic BC $(n=2)$. ctDNA was detected in the plasma of $75 \%$ of patients after cystectomy, which correlated with worse RFS. The median interval between ctDNA detection in plasma and clinical detection of recurrence was 101 days. A similar early detection of recurrence by ctDNA ahead of radiographic detection has been reported for other cancer types [20]. In ten patients with metastatic disease, the authors observed a clear decrease of ctDNA levels during therapy and an increase after cessation of therapy, which correlated with radiographic response to therapy.

While these three contributions offer proof of principle that plasma ctDNA detected by ddPCR may be a valuable test for disease surveillance, the data is relatively heterogenous, and validation in larger and broader patient cohorts is necessary. As outlined above, the ddPCR approach is attractive due to its sensitivity in patients with low tumor burden, but is limited by the low number of mutations captured, and does not accommodate for tumor heterogeneity and molecular evolution over time.

Further application of this type of assay can be projected for patients with both NMIBC and MIBC. Presence versus absence of ctDNA, or relative quantities of ctDNA could be useful for risk stratification. This could be relevant, for example, in patients with high grade $\mathrm{T} 1$ bladder cancer considering intravesical therapy versus immediate radical cystectomy. The administration of adjuvant chemotherapy after radical cystectomy for MIBC could be influenced by the presence of ctDNA in the peripheral blood. Detection of ctDNA could serve as a valuable tool for the early determination of disease recurrence after radical cystectomy or trimodal therapy for MIBC, which in turn would enable administration of early systemic therapy before metastatic disease becomes apparent by radiologic imaging.

A natural extension of using ddPCR to monitor for recurrence and progression in patients with NMIBC and MIBC is to use if for primary disease detection in patients with signs or symptoms of BC but no prior history of BC. Significant efforts are underway to establish protocols using cfDNA for early and noninvasive detection of cancer [21]. It is expected that progress in technical development will significantly reduce costs of current high-throughput approaches, which in turn will promote investigations on ctDNAbased early detection of cancer. In the context of intact primary bladder cancer, analysis of cfDNA in urine 
offers an additional option for disease detection and monitoring [4].

Before ctDNA analysis can be implemented in routine clinical practice to monitor the disease status of BC patients, prospective studies with larger sample sizes are required. If studies confirm the potential of ctDNA analysis to detect recurrence earlier than current tools (urine markers, cystoscopy and imaging), interventional studies based on ctDNA detection could be considered. In the case of MIBC, one potential study design would be to select patients for adjuvant chemotherapy based on results of ctDNA analysis early after cystectomy.

\section{MOLECULAR INTERROGATION OF ADVANCED BC USING CTDNA ANALYSIS}

Higher plasma ctDNA fractions allow for a more extensive characterization of the corresponding tumor genome using NGS. Since ctDNA burden typically corresponds with disease burden, this type of analysis is largely restricted to advanced disease stages [7]. While The Cancer Genome Atlas Project (TCGA) has provided important insight into the genomics and biology of MIBC, there is surprisingly few data available for metastatic urothelial carcinoma [22, 23]. This is in large part due to the fact that metastatic or recurrent BC is rarely biopsied in clinical practice. Theoretically, analysis of plasma ctDNA enables the molecular characterization of the metastatic tumor ecosystem without the need for invasive biopsy. This may be particularly relevant for $\mathrm{BC}$ since a recent study analyzing tissue from multiple metastatic tumor sites of individual patients demonstrated marked heterogeneity between metastases [24]. Furthermore, intra-patient tumor heterogeneity appeared highest in late-stage disease, and would be significantly underestimated using archival primary tissue alone.

A potential advantage of ctDNA analysis is the ability to detect the combined genomic content of all clones from all sites of disease in the context of heterogenous and/or multifocal cancer, provided that each clone releases DNA into circulation. Branched clonal evolution has been described for bladder cancer and other cancers at different tumor sites and under the selective pressure of systemic therapy $[24,25]$.

A gene panel designed to capture key driver mutations and other actionable alterations in $\mathrm{BC}$, as we have previously reported, will inevitably miss some important genomic alterations. However, our panel captures both truncal and some branch mutations. The addition of more genes to such a panel requires increased breadth of sequencing, invariably increases costs.

\section{Identifying therapeutic targets by next generation sequencing (NGS) of ctDNA}

Only two published studies have reported focused data on ctDNA NGS in patients with BC. Patel et al. demonstrated the proof of principle that SNVs can be measured by Tagged Amplicon Sequencing and copy number alterations (CNA) by shallow Whole Genome Sequencing in plasma samples from 17 patients with MIBC receiving neoadjuvant chemotherapy [26]. The assay was designed to analyze SNVs in BRAF, CTNNB1, FGFR3, HRAS, KRAS, NFE2L2, PIK3CA and TP53, which together would capture $72 \%$ of patients with MIBC in the original report from the TCGA [22]. Although SNVs and CNAs were found in 12 and 16, respectively, of 16 tumor samples at baseline, only 6 of 17 patients had detectable SNVs or CNAs in their ctDNA before chemotherapy, and 3 additional patients were found to have alterations during chemotherapy. The most frequent alteration was a mutation in TP53. The detection of tumor-associated aberrations in plasma samples before chemotherapy showed no correlation with response to NAC.

We recently reported results from combined whole exome sequencing (WES) and targeted sequencing of 50 genes relevant to $\mathrm{BC}$ in plasma cfDNA from 51 patients with aggressive $\mathrm{BC}$, including 37 patients with metastatic disease. Using this broad approach, tumor genomic characterization was limited to patients with ctDNA fractions above $2 \%$ (i.e. heterozygous mutations present in plasma at $1 \%$ or higher). This mutation detection threshold (1\%) is routinely selected in conventional NGS studies because it is approximately 10 times the average background error rate (0.1\%) [27]. Accordingly, although only $14 \%$ of patients with localized disease had plasma ctDNA fractions above $2 \%, 73 \%$ of patients with untreated metastatic disease exhibited ctDNA above $2 \%$ and clear tumor associated genomic changes. In previous studies using different technologic approaches, higher rates of patients with localized tumors and detectable ctDNA have been observed showing that our approach has limitations in non-metastatic disease [16]. Among patients with ctDNA above $2 \%$, the ctDNA fraction relative 
to the total cfDNA in the serum ranged from $3.9 \%$ to a remarkable $72.6 \%$ (i.e. more tumor-derived cfDNA than non-malignant cfDNA in the plasma). ctDNA fractions exceeding $30 \%$ were observed exclusively in patients with distant metastatic disease. It seems likely that the majority of ctDNA detected in metastatic patients was shed by metastatic lesions (rather than the primary tumor) as we observed no relationship between cystectomy status and ctDNA fraction. However, we did not assess whether ctDNA burden correlates with metastatic tumor burden (e.g. as assessed by imaging) or number of metastatic lesions.

In patients receiving chemotherapy, we noted that total cfDNA yields from plasma were high regardless of disease stage. Since ctDNA fractions did not appear to be concomitantly elevated, we hypothesize this could reflect increased cfDNA released by dying non-malignant cells affected by chemotherapy. To validate this hypothesis, future studies could explore the spacing of nucleosome footprints in cfDNA to identify putative predominant cell-oforigin. This approach has been shown to enable a characterization of the origin of cells independent of observed genomic alterations [28]. In our study, the TP53 gene was the most commonly altered, affected in 65\% (17/26) of patients; higher than the $49 \%$ rate observed in the TCGA cohort [22]. Further cell-cycle associated genes with frequent aberrations included RB1 and CDKN2A. A high proportion of patients (19/26) showed aberrations in at least one chromatin remodeling gene (including ARID1A and KMT2D). Alterations in the PI3K/mTOR pathway were observed in a significant proportion of metastatic patients. Genomic alterations in the MAPK pathway were detected in $15 / 26$ patients with evidence of ctDNA, including nine patients with ERBB2 activating changes (either hotspot mutations or gene amplifications). Using capture probes tiled across the introns of FGFR3, we were able to detect (in multiple samples from one patient) a previously unreported gene fusion of FGFR3 and ADD1 potentially leading to overactivation of FGFR3 (similar to the well-established FGFR3-TACC3 fusion gene).

The identification of diverse mutations, copy number changes, and chromosomal rearrangements in our study suggests that ctDNA may be useful for guiding molecularly targeted therapy in advanced BC. For example, detection of FGFR3 fusion genes or ERBB2 amplifications or mutations could identify patients susceptible to FGFR3 or ERBB2 inhibitors, respectively [29]. In clinical trials ERBB2 genomic alterations have been shown to predict sensitivity to a specific HER2 inhibition [30] and FGFR alterations also predict response to FGFR inhibition [31, 32]. Moreover, patients with TSC1/TSC2 alterations may be good candidates for mTOR inhibition (everolimus) [33]. Whether plasma ctDNA analysis can be used as a tool for next generation clinical trials, including especially umbrella or basket trials, is a matter of current debate [34]. First trials using ctDNA analysis in this context have been initiated in various solid malignancies [35].

\section{Markers of response to therapy in ctDNA}

Similarly, molecular markers predicting resistance or response to currently approved drugs may be identified in ctDNA. For example, detection of mutations in ERCC2 or other DNA repair genes could be used to identify patients likely to respond to cisplatin-based chemotherapy [36-39]. This type of genomic prediction could streamline care to avoid ineffective and expensive treatments and instead prioritize the most effective therapies.

Since high mutational load in BC tumor tissue is proposed as a potential biomarker for patient response to immune checkpoint blockade, we have suggested that assessment of the mutation rate using plasma ctDNA should be tested for its ability to predict response [40, 41]. In our cohort, $12 \%$ of patients had projected mutation rates above 30 per $\mathrm{MB}$, a threshold that has been identified in the tissue of other cancers to be associated with response to immunotherapy. In a subgroup of patients, we performed WES and compared mutation rates derived from WES with rates derived from targeted sequencing. Although higher mutation rates were measured by targeted sequencing compared to WES, estimated somatic mutation rates correlated significantly between both methods. The higher mutation rate in targeted sequencing may result from a bias towards recurrent driver mutations in the targeted gene panel, as well as the ability of deep targeted sequencing to detect low allele frequency sub-clonal mutations that are missed by conventional WES. This observation highlights the need to determine thresholds for 'high' mutational load that are specific to the assay in question. Furthermore, the specific type of mutation, not just overall mutation rate, may be important. A recent analysis of 5777 solid tumours from 19 cancer types suggested that insertion or deletion (indel) mutations may be associated with higher neoantigen immunogenicity 
compared to non-synonymous single nucleotide variants (SNVs). In a subset of 38 melanoma patients, higher counts of frameshift indel mutations were significantly associated with response to PD-1 inhibition [42]. High rates of indels in kidney tumors may also help explain the responses observed to immune checkpoint blockade in that cancer type, despite an overall low mutation rate on average. Future studies must address these critical knowledge gaps in BC.

The analysis of plasma samples collected in the framework of currently ongoing phase III trials using immunotherapy in urothelial carcinoma will hopefully provide more insight into a potential correlation between neoantigen burden and response to immunotherapy. If such a correlation can be confirmed, prospective interventional trials selecting treatment type (chemotherapy or immunotherapy) based on liquid biopsy profiles could be considered.

In a recent study presented at ASCO 2017, Kuziora et al. analyzed plasma ctDNA using a targeted sequencing panel of 70 genes in 29 patients with metastatic urothelial carcinoma before treatment and after 6 weeks of treatment with the PD-L1 inhibitor durvalumab in the framework of a phase II trial [43]. In accordance with our own data, the genes most frequently altered in pre-treatment samples were TP53 (73\%) and ARID1A (55\%). The authors did not assess mutational burden at baseline as a predictor of response, as we propose above, but instead investigated whether changes in variant allele frequency (VAF) on treatment correlated with response. Compared to baseline, patients with response to durvalumab showed a significant decrease in the variant allele frequency after 6 weeks of treatments $(-2.36 \%, p=0.02)$, whereas no significant changes in VAF were detected in patients with progressive disease $(+2.69 \%, p=0.31)$. Moreover, patients with response to durvalumab had a decreased mutation count after 6 weeks of treatment $(-4.6$ counts, $p=0.003$ ) whereas no significant change was detected in patients with progressive disease $(+2.78$ counts, $p=0.436$ ). Patients showing a decrease in the VAF after 6 weeks had a significantly better PFS and OS. These data suggest that changes in cfDNA profiles detected during an early phase of treatment may serve as a surrogate parameter of response to treatment and improved outcome. Future studies should examine whether lack of ctDNA decline on treatment can be used as a tool to identify patients who will not respond to a given therapy, and therefore facilitate an earlier change in therapy

\section{ctDNA in the context of tumor heterogeneity}

It is not yet possible to determine whether genomic aberrations present in the plasma ctDNA originate from multiple lesions or from a single progressing lesion. Molecular heterogeneity is as much of a concern in $\mathrm{BC}$ as it is in most cancers, such that a putative target or marker of drug response may only be present in part of a tumor or in one tumor site $[44,45]$. As described above, the seminal study from Faltas and colleagues described remarkable intra-patient tumor heterogeneity in BC [24]. In theory ctDNA could reflect the totality of all tumor sites, or at least the predominant tumor clone. Longitudinal testing over time would allow emerging clones to be identified promptly. To assess how multiple lesions affect the profile of ctDNA in patients with metastatic BC, future studies comparing multiple metastatic sites and ctDNA will be needed. A rapid autopsy program could provide a suitable setting for this type of study [46].

In this context Cheng et al. reported at ASCO 2017 on correlations between ctDNA analysis and

Table 2

Potential applications of ctDNA analysis in patients with different bladder cancer (BC) disease states

\begin{tabular}{llr}
\hline Disease State & Potential Application of ctDNA & References \\
\hline NMIBC & - Screening/Diagnosis & {$[8]$} \\
& - Risk stratification: Prediction of recurrence/progression & {$[9]$} \\
& - Prediction of response to intravesical therapy & {$[26]$} \\
- Monitoring for recurrence & {$[10]$} \\
& - Risk stratification: Prediction of recurrence/survival & {$[10]$} \\
& - Prediction of response to neoadjuvant chemotherapy & {$[47]$} \\
& - Decision aide for adjuvant chemotherapy for clinically occult disease (+ctDNA) & {$[43]$} \\
& - Monitoring for recurrence & \\
& - Determination of mutational load (as putative marker of response to immunotherapy) \\
& - Liquid biopsy for molecular characterization & \\
& - Determine presence of target for targeted therapy &
\end{tabular}


profiling of archival tissue in 15 patients with metastatic urothelial carcinoma using a capturebased NGS assay targeting 341-468 genes [47]. In the whole cohort of patients $(n=26$, including patients with missing archival tissue), at least one somatic mutation was detected in ctDNA of $69 \%$ of patients, but the same alterations were not present in the tumor tissue in $40 \%$ of cases. On the other hand, $73 \%$ of patients exhibited alterations in archival tissue that were not detected in plasma. An identical mutation profile in tissue and plasma was detected in $20 \%$ of patients. The interval between tumor tissue sampling and plasma sampling in these patients was between 35 days and 1.5 years. These findings underline the potential added value of plasma ctDNA analysis compared to sequencing of archival tumor tissue, which might not reflect the current status of disease.

\section{SUMMARY}

Bladder cancer exhibits a high mutational burden compared to other solid tumors. This characteristic means that bladder cancer is particularly suited for ctDNA analysis, as 'diluted' mutant alleles can now be robustly detected in peripheral blood using state-of-the-art technologies. In the context of disease surveillance, initial studies have shown that specific ddPCR assays facilitate early and highly sensitive detection of disease recurrence. In patients with metastatic BC, early targeted NGS studies have demonstrated that the vast majority of progressing patients have high levels of ctDNA in their blood and harbor genomic aberrations that may associate with differential sensitivity to specific drugs. In addition to its potential utility in surveillance and identification of treatment-relevant genes, ctDNA may also be a valuable tool for detection of markers of response to therapy and other components of patient management (Table 2). This is a burgeoning field of study with many new discoveries likely in the near future.

\section{ACKNOWLEDGMENTS}

None.

\section{CONFLICTS OF INTEREST}

No relevant conflicts of interest.

\section{REFERENCES}

[1] Hegemann M, Stenzl A, Bedke J, Chi KN, Black PC, Todenhofer T. Liquid biopsy: Ready to guide therapy in advanced prostate cancer? BJU International 2016;118(6): 855-63.

[2] Alix-Panabieres C, Pantel K. Clinical applications of circulating tumor cells and circulating tumor DNA as liquid biopsy. Cancer Discovery 2016;6(5):479-91.

[3] Leon SA, Shapiro B, Sklaroff DM, Yaros MJ. Free DNA in the serum of cancer patients and the effect of therapy. Cancer Research 1977;37(3):646-50.

[4] Olsson E, Winter C, George A, Chen Y, Howlin J, Tang MH, Dahlgren M, Schulz R, Grabau D, van Westen D, Ferno M, Ingvar C, Rose C, Bendahl PO, Ryden L, Borg A, Gruvberger-Saal SK, Jernstrom H, Saal LH. Serial monitoring of circulating tumor DNA in patients with primary breast cancer for detection of occult metastatic disease. EMBO Molecular Medicine 2015;7(8):1034-47.

[5] Goodall J, Mateo J, Yuan W, Mossop H, Porta N, Miranda S, Perez-Lopez R, Dolling D, Robinson DR, Sandhu S, Fowler G, Ebbs B, Flohr P, Seed G, Rodrigues DN, Boysen G, Bertan C, Atkin M, Clarke M, Crespo M, Figueiredo I, Riisnaes R, Sumanasuriya S, Rescigno P, Zafeiriou Z, Sharp A, Tunariu N, Bianchini D, Gillman A, Lord CJ, Hall E, Chinnaiyan AM, Carreira S, de Bono JS, investigators T-A. Circulating Free DNA to Guide Prostate Cancer Treatment with PARP Inhibition. Cancer Discovery 2017.

[6] Wyatt AW, Annala M, Aggarwal R, Beja K, Feng F, Youngren J, Foye A, Lloyd P, Nykter M, Beer TM, Alumkal JJ, Thomas GV, Reiter RE, Rettig MB, Evans CP, Gao AC, Chi KN, Small EJ, Gleave ME. Concordance of Circulating Tumor DNA and Matched Metastatic Tissue Biopsy in Prostate Cancer. JNCI: Journal of the National Cancer Institute 2017;109(12):djx118-djx118

[7] Bettegowda C, Sausen M, Leary RJ, Kinde I, Wang Y, Agrawal N, Bartlett BR, Wang H, Luber B, Alani RM, Antonarakis ES, Azad NS, Bardelli A, Brem H, Cameron JL, Lee CC, Fecher LA, Gallia GL, Gibbs P, Le D, Giuntoli RL, Goggins M, Hogarty MD, Holdhoff M, Hong SM, Jiao Y, Juhl HH, Kim JJ, Siravegna G, Laheru DA, Lauricella C, Lim M, Lipson EJ, Marie SK, Netto GJ, Oliner KS, Olivi A, Olsson L, Riggins GJ, Sartore-Bianchi A, Schmidt K, Shih 1 M, Oba-Shinjo SM, Siena S, Theodorescu D, Tie J, Harkins TT, Veronese S, Wang TL, Weingart JD, Wolfgang CL, Wood LD, Xing D, Hruban RH, Wu J, Allen PJ, Schmidt CM, Choti MA, Velculescu VE, Kinzler KW, Vogelstein B, Papadopoulos N, Diaz LA Jr. Detection of circulating tumor DNA in early- and late-stage human malignancies. Science Translational Medicine 2014;6(224):224ra224.

[8] Birkenkamp-Demtroder K, Nordentoft I, Christensen E, Hoyer S, Reinert T, Vang S, Borre M, Agerbaek M, Jensen JB, Orntoft TF, Dyrskjot L. Genomic Alterations in Liquid Biopsies from Patients with Bladder Cancer. European Urology 2016;70(1):75-82.

[9] Christensen E, Birkenkamp-Demtroder K, Nordentoft I, Hoyer S, van der Keur K, van Kessel K, Zwarthoff E, Agerbaek M, Orntoft TF, Jensen JB, Dyrskjot L. Liquid Biopsy Analysis of FGFR3 and PIK3CA Hotspot Mutations for Disease Surveillance in Bladder Cancer. European Urology 2017;71(6):961-9.

[10] Vandekerkhove G, Todenhöfer T, Annala M, Struss W, Wong A, Beja K, Ritch E, Brahmbhatt S, Volik S, Hennenlotter J, Nykter M, Chi KN, North S, Stenzl A, Collins CC, Eigl BJ, Black PC, Wyatt AW. Circulating 
tumor DNA reveals clinically-actionable somatic genome of metastatic bladder cancer. Clinical Cancer Research: An Official Journal of the American Association for Cancer Research 2017.

[11] Schwarzenbach H, Hoon DS, Pantel K. Cell-free nucleic acids as biomarkers in cancer patients. Nature Reviews Cancer 2011;11(6):426-37.

[12] Khalaf D, Annala M, Beja K, Vandekerkhove G, Zulfiqar M, Finch DL, Oja CD, Vergidis J, Gleave M, Wyatt AW, Chi KN. Circulating tumor DNA (ctDNA) and correlations with clinical prognostic factors in patients with metastatic castration-resistant prostate cancer (mCRPC). Journal of Clinical Oncology 2017;35(6_suppl):186.

[13] Husain H, Velculescu VE. Cancer DNA in the circulation: The liquid biopsy. Jama 2017;318(13):1272-74.

[14] Newman AM, Bratman SV, To J, Wynne JF, Eclov NC, Modlin LA, Liu CL, Neal JW, Wakelee HA, Merritt RE, Shrager JB, Loo BW Jr, Alizadeh AA, Diehn M. An ultrasensitive method for quantitating circulating tumor DNA with broad patient coverage. Nature Medicine 2014;20(5): 548-54.

[15] Robertson AG, Kim J, Al-Ahmadie H, Bellmunt J, Guo G, Cherniack AD, Hinoue T, Laird PW, Hoadley KA, Akbani R, Castro MAA, Gibb EA, Kanchi RS, Gordenin DA, Shukla SA, Sanchez-Vega F, Hansel DE, Czerniak BA, Reuter VE, Su X, de Sa Carvalho B, Chagas VS, Mungall KL, Sadeghi S, Pedamallu CS, Lu Y, Klimczak LJ, Zhang J, Choo C, Ojesina AI, Bullman S, Leraas KM, Lichtenberg TM, Wu CJ, Schultz N, Getz G, Meyerson M, Mills GB, McConkey DJ, Network TR, Weinstein JN, Kwiatkowski DJ, Lerner SP. Comprehensive molecular characterization of muscle-invasive bladder cancer. Cell 2017;171(3):540556 e 525.

[16] Birkenkamp-Demtroder K, Christensen E, Nordentoft I, Knudsen M, Taber A, Hoyer S, Lamy P, Agerbaek M, Jensen JB, Dyrskjot L. Monitoring treatment response and metastatic relapse in advanced bladder cancer by liquid biopsy analysis. European Urology 2017.

[17] Vandekerkhove G, Todenhofer T, Annala M, Struss WJ, Wong A, Beja K, Ritch E, Brahmbhatt S, Volik SV, Hennenlotter J, Nykter M, Chi KN, North S, Stenzl A, Collins CC, Eigl BJ, Black PC, Wyatt AW. Circulating tumor DNA reveals clinically actionable somatic genome of metastatic bladder cancer. Clinical Cancer Research: An Official Journal of the American Association for Cancer Research 2017.

[18] Serizawa RR, Ralfkiaer U, Steven K, Lam GW, Schmiedel S, Schuz J, Hansen AB, Horn T, Guldberg P. Integrated genetic and epigenetic analysis of bladder cancer reveals an additive diagnostic value of FGFR3 mutations and hypermethylation events. International Journal of Cancer 2011;129(1):78-87.

[19] Zuiverloon TC, Tjin SS, Busstra M, Bangma CH, Boeve ER, Zwarthoff EC. Optimization of nonmuscle invasive bladder cancer recurrence detection using a urine based FGFR3 mutation assay. The Journal of Urology 2011;186(2): 707-12.

[20] Tie J, Kinde I, Wang Y, Wong HL, Roebert J, Christie M, Tacey M, Wong R, Singh M, Karapetis CS, Desai J, Tran B, Strausberg RL, Diaz LA Jr, Papadopoulos N, Kinzler KW, Vogelstein B, Gibbs P. Circulating tumor DNA as an early marker of therapeutic response in patients with metastatic colorectal cancer. Annals of Oncology: Official Journal of the European Society for Medical Oncology/ESMO 2015;26(8):1715-22.
[21] Aravanis AM, Lee M, Klausner RD. Next-generation sequencing of circulating tumor DNA for early cancer detection. Cell 2017;168(4):571-4.

[22] Cancer Genome Atlas Research N. Comprehensive molecular characterization of urothelial bladder carcinoma. Nature 2014;507(7492):315-22.

[23] Seiler R, Black PC, Thalmann G, Stenzl A, Todenhofer T. Is The Cancer Genome Atlas (TCGA) bladder cancer cohort representative of invasive bladder cancer? Urologic Oncology 2017;35(7):458 e451-458 e457.

[24] Faltas BM, Prandi D, Tagawa ST, Molina AM, Nanus DM, Sternberg C, Rosenberg J, Mosquera JM, Robinson B, Elemento O, Sboner A, Beltran H, Demichelis F, Rubin MA. Clonal evolution of chemotherapy-resistant urothelial carcinoma. Nature Genetics 2016;48(12):1490-9.

[25] Abbosh C, Birkbak NJ, Wilson GA, Jamal-Hanjani M, Constantin T, Salari R, Le Quesne J, Moore DA, Veeriah S, Rosenthal R, Marafioti T, Kirkizlar E, Watkins TBK, McGranahan N, Ward S, Martinson L, Riley J, Fraioli F, Al Bakir M, Gronroos E, Zambrana F, Endozo R, Bi WL, Fennessy FM, Sponer N, Johnson D, Laycock J, Shafi S, Czyzewska-Khan J, Rowan A, Chambers T, Matthews N, Turajlic S, Hiley C, Lee SM, Forster MD, Ahmad T, Falzon M, Borg E, Lawrence D, Hayward M, Kolvekar S, Panagiotopoulos N, Janes SM, Thakrar R, Ahmed A, Blackhall F, Summers Y, Hafez D, Naik A, Ganguly A, Kareht S, Shah R, Joseph L, Marie Quinn A, Crosbie PA, Naidu B, Middleton G, Langman G, Trotter S, Nicolson M, Remmen H, Kerr K, Chetty M, Gomersall L, Fennell DA, Nakas A, Rathinam S, Anand G, Khan S, Russell P, Ezhil V, Ismail B, Irvin-Sellers M, Prakash V, Lester JF, Kornaszewska M, Attanoos R, Adams H, Davies H, Oukrif D, Akarca AU, Hartley JA, Lowe HL, Lock S, Iles N, Bell H, Ngai Y, Elgar G, Szallasi Z, Schwarz RF, Herrero J, Stewart A, Quezada SA, Peggs KS, Van Loo P, Dive C, Lin CJ, Rabinowitz M, Aerts H, Hackshaw A, Shaw JA, Zimmermann BG, consortium TR, consortium P, Swanton C. Phylogenetic ctDNA analysis depicts early-stage lung cancer evolution. Nature 2017;545(7655):446-51.

[26] Patel KM, van der Vos KE, Smith CG, Mouliere F, Tsui D, Morris J, Chandrananda D, Marass F, van den Broek D, Neal DE, Gnanapragasam VJ, Forshew T, van Rhijn BW, Massie CE, Rosenfeld N, van der Heijden MS. Association of plasma and urinary mutant DNA with clinical outcomes in muscle invasive bladder cancer. Scientific Reports 2017;7(1):5554.

[27] Phallen J, Sausen M, Adleff V, Leal A, Hruban C, White J, Anagnostou V, Fiksel J, Cristiano S, Papp E, Speir S, Reinert T, Orntoft MW, Woodward BD, Murphy D, Parpart-Li S, Riley D, Nesselbush M, Sengamalay N, Georgiadis A, Li QK, Madsen MR, Mortensen FV, Huiskens J, Punt C, van Grieken N, Fijneman R, Meijer G, Husain H, Scharpf RB, Diaz LA, Jr., Jones S, Angiuoli S, Orntoft T, Nielsen HJ, Andersen CL, Velculescu VE. Direct detection of early-stage cancers using circulating tumor DNA. Science Translational Medicine 2017;9(403).

[28] Snyder MW, Kircher M, Hill AJ, Daza RM, Shendure J. Cell-free DNA comprises an in vivo nucleosome footprint that informs its tissues-of-origin. Cell 2016;164(1-2): 57-68.

[29] Kiss B, Wyatt AW, Douglas J, Skuginna V, Mo F, Anderson S, Rotzer D, Fleischmann A, Genitsch V, Hayashi T, Neuenschwander M, Buerki C, Davicioni E, Collins C, Thalmann GN, Black PC, Seiler R. Her2 alterations in muscle- 
invasive bladder cancer: Patient selection beyond protein expression for targeted therapy. Scientific Reports 2017;7: 42713.

[30] Choudhury NJ, Campanile A, Antic T, Yap KL, Fitzpatrick CA, Wade JL 3rd, Karrison T, Stadler WM, Nakamura Y, O'Donnell PH. Afatinib Activity in PlatinumRefractory Metastatic Urothelial Carcinoma in Patients With ERBB Alterations. Journal of Clinical Oncology: Official Journal of the American Society of Clinical Oncology 2016;34(18):2165-71.

[31] Gust KM, McConkey DJ, Awrey S, Hegarty PK, Qing J, Bondaruk J, Ashkenazi A, Czerniak B, Dinney CP, Black PC. Fibroblast growth factor receptor 3 is a rational therapeutic target in bladder cancer. Molecular Cancer Therapeutics 2013;12(7):1245-54

[32] Nogova L, Sequist LV, Perez Garcia JM, Andre F, Delord JP, Hidalgo M, Schellens JH, Cassier PA, Camidge DR, Schuler M, Vaishampayan U, Burris H, Tian GG, Campone M, Wainberg ZA, Lim WT, LoRusso P, Shapiro GI, Parker K, Chen X, Choudhury S, Ringeisen F, Graus-Porta D, Porter D, Isaacs R, Buettner R, Wolf J. Evaluation of BGJ398, a fibroblast growth factor receptor 1-3 kinase inhibitor, in patients with advanced solid tumors harboring genetic alterations in fibroblast growth factor receptors: Results of a global phase I, dose-escalation and dose-expansion study. Journal of Clinical Oncology: Official Journal of the American Society of Clinical Oncology 2017;35(2): 157-65.

[33] Wagle N, Grabiner BC, Van Allen EM, Hodis E, Jacobus S, Supko JG, Stewart M, Choueiri TK, Gandhi L, Cleary JM, Elfiky AA, Taplin ME, Stack EC, Signoretti S, Loda M, Shapiro GI, Sabatini DM, Lander ES, Gabriel SB, Kantoff PW, Garraway LA, Rosenberg JE. Activating mTOR mutations in a patient with an extraordinary response on a phase I trial of everolimus and pazopanib. Cancer Discovery 2014;4(5):546-53.

[34] Siu LL, Conley BA, Boerner S, LoRusso PM. NextGeneration Sequencing to Guide Clinical Trials. Clinical Cancer Research: An Official Journal of the American Association for Cancer Research 2015;21(20):4536-44.

[35] Kim ST, Talasaz A, Park SH, Kang WK, Eltoukhy H, Lanman RB, Lee J, Park K. The NEXT-2 (Next Generation Personalized Tx with Plasma DNA Genomics Trial2 in Refractory Solid Tumors: cfDNA-Based Umbrella Trial, an interim analysis). Journal of Clinical Oncology 2015;33(15_suppl):e12540.

[36] Liu D, Plimack ER, Hoffman-Censits J, Garraway LA, Bellmunt J, Van Allen E, Rosenberg JE. Clinical validation of chemotherapy response biomarker ERCC2 in muscleinvasive urothelial bladder carcinoma. JAMA Oncology 2016;2(8):1094-6.

[37] Plimack ER, Dunbrack RL, Brennan TA, Andrake MD, Zhou Y, Serebriiskii IG, Slifker M, Alpaugh K, Dulaimi E, Palma N, Hoffman-Censits J, Bilusic M, Wong YN, Kutikov A, Viterbo R, Greenberg RE, Chen DY, Lallas CD, Trabulsi EJ, Yelensky R, McConkey DJ, Miller VA, Golemis EA, Ross EA. Defects in DNA repair genes predict response to neoadjuvant cisplatin-based chemotherapy in muscle-invasive bladder cancer. European Urology 2015;68(6):959-67.

[38] Teo MY, Bambury RM, Zabor EC, Jordan E, Al-Ahmadie H, Boyd ME, Bouvier N, Mullane SA, Cha EK, Roper $\mathrm{N}$, Ostrovnaya I, Hyman DM, Bochner BH, Arcila ME, Solit DB, Berger MF, Bajorin DF, Bellmunt J, Iyer
G, Rosenberg JE. DNA damage response and repair gene alterations are associated with improved survival in patients with platinum-treated advanced urothelial carcinoma. Clinical Cancer Research: An Official Journal of the American Association for Cancer Research 2017;23(14): 3610-8.

[39] Van Allen EM, Mouw KW, Kim P, Iyer G, Wagle N, AlAhmadie H, Zhu C, Ostrovnaya I, Kryukov GV, O’Connor KW, Sfakianos J, Garcia-Grossman I, Kim J, Guancial EA, Bambury R, Bahl S, Gupta N, Farlow D, Qu A, Signoretti S, Barletta JA, Reuter V, Boehm J, Lawrence M, Getz G, Kantoff P, Bochner BH, Choueiri TK, Bajorin DF, Solit DB, Gabriel S, D'Andrea A, Garraway LA, Rosenberg JE. Somatic ERCC2 mutations correlate with cisplatin sensitivity in muscle-invasive urothelial carcinoma. Cancer Discovery 2014;4(10):1140-53.

[40] Rosenberg JE, Hoffman-Censits J, Powles T, van der Heijden MS, Balar AV, Necchi A, Dawson N, O’Donnell PH, Balmanoukian A, Loriot Y, Srinivas S, Retz MM, Grivas P, Joseph RW, Galsky MD, Fleming MT, Petrylak DP, PerezGracia JL, Burris HA, Castellano D, Canil C, Bellmunt J, Bajorin D, Nickles D, Bourgon R, Frampton GM, Cui N, Mariathasan S, Abidoye O, Fine GD, Dreicer R. Atezolizumab in patients with locally advanced and metastatic urothelial carcinoma who have progressed following treatment with platinum-based chemotherapy: A singlearm, multicentre, phase 2 trial. Lancet 2016;387(10031): 1909-20.

[41] Sharma P, Retz M, Siefker-Radtke A, Baron A, Necchi A, Bedke J, Plimack ER, Vaena D, Grimm MO, Bracarda S, Arranz JA, Pal S, Ohyama C, Saci A, Qu X, Lambert A, Krishnan S, Azrilevich A, Galsky MD. Nivolumab in metastatic urothelial carcinoma after platinum therapy (CheckMate 275): A multicentre, single-arm, phase 2 trial. The Lancet Oncology 2017;18(3):312-22.

[42] Turajlic S, Litchfield K, Xu H, Rosenthal R, McGranahan N, Reading JL, Wong YNS, Rowan A, Kanu N, Al Bakir M, Chambers T, Salgado R, Savas P, Loi S, Birkbak NJ, Sansregret L, Gore M, Larkin J, Quezada SA, Swanton C. Insertion-and-deletion-derived tumour-specific neoantigens and the immunogenic phenotype: A pan-cancer analysis. The Lancet Oncology 2017;18(8):1009-21.

[43] Kuziora M, Higgs BW, Bohawn PZ, Bais C, Gupta A, Antal J, Ranade K. Early Reduction in circulating tumor DNA is associated with improved progression-free survival and overall survival of urothelial carcinoma patients treated with durvalumab. Journal of Clinical Oncology: Official Journal of the American Society of Clinical Oncology 2017;35(15 suppl): 11538 .

[44] Thomsen MB, Nordentoft I, Lamy P, Hoyer S, Vang S, Hedegaard J, Borre M, Jensen JB, Orntoft TF, Dyrskjot L. Spatial and temporal clonal evolution during development of metastatic urothelial carcinoma. Mol Oncol 2016;10(9):1450-60.

[45] Alderton GK. Tumour evolution: Epigenetic and genetic heterogeneity in metastasis. Nature Reviews Cancer 2017;17(3): 141.

[46] Savas P, Teo ZL, Lefevre C, Flensburg C, Caramia F, Alsop K, Mansour M, Francis PA, Thorne HA, Silva MJ, Kanu N, Dietzen M, Rowan A, Kschischo M, Fox S, Bowtell DD, Dawson SJ, Speed TP, Swanton C, Loi S. The subclonal architecture of metastatic breast cancer: Results from a prospective community-based rapid autopsy program “CASCADE". PLoS Medicine 2016;13(12):e1002204. 
[47] Cheng L, Shady M, Cipolla CK, Funt S, Arcila ME, AlAhmadie H, Rosenberg JE, Barjorin DF, Berger MF, Tsui D, Solit DB, Iyer G. Comparison of somatic mutation profiles from cell free DNA (cfDNA) versus tissue in metastatic urothelial carcinoma (mUC). Journal of Clinical Oncology: Official Journal of the American Society of Clinical Oncology 2017;35(15_suppl):4533.

[48] Conteduca V, Wetterskog D, Sharabiani MTA, Grande E, Fernandez-Perez MP, Jayaram A, Salvi S, Castellano D, Romanel A, Lolli C, Casadio V, Gurioli G, Amadori D, Font A, Vazquez-Estevez S, Gonzalez Del Alba A, Mellado B, Fernandez-Calvo O, Mendez-Vidal MJ, Climent MA, Duran I, Gallardo E, Rodriguez A, Santander C, Saez MI, Puente J, Gasi Tandefelt D, Wingate A, Dearnaley D, Collaborators P, Spanish Oncology Genitourinary G, Demichelis F,
De Giorgi U, Gonzalez-Billalabeitia E, Attard G. Androgen receptor gene status in plasma DNA associates with worse outcome on enzalutamide or abiraterone for castrationresistant prostate cancer: A multi-institution correlative biomarker study. Annals of Oncology: Official Journal of the European Society for Medical Oncology/ESMO 2017;28(7):1508-16.

[49] Newman AM, Lovejoy AF, Klass DM, Kurtz DM, Chabon JJ, Scherer F, Stehr H, Liu CL, Bratman SV, Say C, Zhou L, Carter JN, West RB, Sledge GW, Shrager JB, Loo BW Jr, Neal JW, Wakelee HA, Diehn M, Alizadeh AA. Integrated digital error suppression for improved detection of circulating tumor DNA. Nature Biotechnology 2016;34(5): 547-55. 